

\title{
Differential antibacterial activity against Pseudomonas aeruginosa by carbon monoxide-releasing molecules.
} Mathieu Desmard, Roberta Foresti, Didier Morin, Maylis Dagoussat, Alain Berdeaux, Erick Denamur, Sian H. Crook, Brian E. Mann, David Scapens, Philippe Montravers, et al.

\section{To cite this version:}

Mathieu Desmard, Roberta Foresti, Didier Morin, Maylis Dagoussat, Alain Berdeaux, et al.. Differential antibacterial activity against Pseudomonas aeruginosa by carbon monoxide-releasing molecules.. Antioxidants and Redox Signaling, 2012, 16 (2), pp.153-63. 10.1089/ars.2011.3959 . inserm00656413

\section{HAL Id: inserm-00656413 https://www.hal.inserm.fr/inserm-00656413}

Submitted on 4 Jan 2012

HAL is a multi-disciplinary open access archive for the deposit and dissemination of scientific research documents, whether they are published or not. The documents may come from teaching and research institutions in France or abroad, or from public or private research centers.
L'archive ouverte pluridisciplinaire HAL, est destinée au dépôt et à la diffusion de documents scientifiques de niveau recherche, publiés ou non, émanant des établissements d'enseignement et de recherche français ou étrangers, des laboratoires publics ou privés. 


\title{
Differential Antibacterial Activity Against Pseudomonas aeruginosa by Carbon Monoxide-Releasing Molecules
}

\author{
Mathieu Desmard, ${ }^{1,2}$ Roberta Foresti, ${ }^{3}$ Didier Morin, ${ }^{4}$ Maylis Dagouassat, Alain Berdeaux ${ }^{4}$ \\ Erick Denamur, ${ }^{5}$ Sian H. Crook, ${ }^{6}$ Brian E. Mann, ${ }^{6}$ David Scapens, ${ }^{6}$ Philippe Montravers, ${ }^{2}$ \\ Jorge Boczkowski, ${ }^{1,7,8, *}$ and Roberto Motterlini ${ }^{3,4, *}$
}

\begin{abstract}
Aims: Carbon monoxide (CO) delivered in a controlled manner to cells and organisms mediates a variety of pharmacological effects to the extent that CO-releasing molecules (CO-RMs) are being developed for therapeutic purposes. Recently, ruthenium-based CO-RMs have been shown to posses important bactericidal activity. Here we assessed the effect of fast $\mathrm{CO}$ releasers containing ruthenium $\left(\mathrm{Ru}(\mathrm{CO})_{3} \mathrm{Cl}(\right.$ glycinate) [CORM-3] and tricarbonyldichlororuthenium(II) dimer [CORM-2]) and a novel slow manganese-based CO releaser $\left(\left[\mathrm{Me}_{4} \mathrm{~N}\right]\right.$ $\left.\left[\mathrm{Mn}(\mathrm{CO})_{4} \text { (thioacetate }\right)_{2}\right]$ [CORM-371]) on $\mathrm{O}_{2}$ consumption and growth of Pseudomonas aeruginosa (PAO1). We then compared these effects with the action elicited by sodium boranocarbonate (CORM-A1), which lacks a transition metal but liberates CO with a rate similar to CORM-371. Results: CORM-2, CORM-3, and, to a lesser extent, CORM-371 exerted a significant bactericidal effect and decreased $\mathrm{O}_{2}$ consumption in PAO1 in vitro. The effect appeared to be independent of reactive oxygen species production, but in the case of metal-containing compounds it was prevented by the thiol donor $\mathrm{N}$-acetylcysteine. In contrast, CORM-A1 was bacteriostatic rather than bactericidal in vitro eliciting only a moderate and transient decrease in $\mathrm{O}_{2}$ consumption. Innovation: None of the tested CO-RMs was toxic to murine macrophages or human fibroblasts at the concentration impairing PA01 growth but only ruthenium-containing CO-RMs showed potential therapeutic properties by increasing the survival of mice infected with PA01. Conclusion: $\mathrm{CO}$ carriers inhibit bacterial growth and $\mathrm{O}_{2}$ consumption in vitro, but transition metal carbonyls appear more powerful than compounds spontaneously liberating CO. The nature of the metal in CO-RMs also modulates the anti-bacterial effect, with ruthenium-based CO-RMs being efficacious both in vitro and in vivo. Antioxid. Redox Signal. 16, 153-163.
\end{abstract}

\section{Introduction}

C ARBON MONOXIDE (CO) Is a stable gas that occurs in nature as a product of incomplete oxidation or combustion of organic matter. It is perceived as a highly toxic pollutant although small quantities of this gas are produced endogenously in plants, bacteria, and animals through heme metabolism by heme oxygenase enzymes, which serve to detoxify cells from harmful chemicals and protect against oxidative stress $(31,10,43,8)$. The finding that $\mathrm{CO}$ interacts effectively with several intracellular heme-containing targets (i.e., soluble guanylate cyclase, cytochrome c oxidase, NADPH oxidase, and BK potassium channels) to transduce important cellular signals has intensified the investigation on the biological properties of this gaseous molecule (6). Indeed, it has been demonstrated that $\mathrm{CO}$ exerts important biological activities, including vasorelaxation, resolution of inflammatory states, as well as anti-apoptotic and cytoprotective actions in various models of disease $(26,33)$. Binding of $\mathrm{CO}$ to ferrous iron and other metal centers is thought to mediate some of its biological effects; for example, in eukaryotic cells $\mathrm{CO}$ at high concentrations targets mitochondrial cytochrome $\mathrm{c}$

\footnotetext{
${ }^{1}$ Inserm U955, equipe 4, Université Paris Est, Faculté de Médecine, Creteil, France.

${ }^{2}$ Département Anesthésie-Réanimation Chirurgicale, Assistance Publique-Hôpitaux de Paris, Hôpital Bichat-Claude Bernard, Paris, France.

${ }^{3}$ Department of Drug Discovery and Development, Italian Institute of Technology, Genova, Italy.

${ }^{4}$ Inserm U955, équipe 3, Université Paris Est, Faculté de Médecine, Creteil, France.

${ }^{5}$ Inserm U722, Université Paris 7, Faculté de Médecine, Xavier Bichat, Paris, France.

${ }^{6}$ Department of Chemistry, University of Sheffield, Sheffield, United Kingdom.

${ }^{7}$ Service de Physiologie Explorations Fonctionnelles, Assistance Publique-Hôpitaux de Paris, Hôpital Henri-Mondor, Créteil, France.

${ }^{8}$ Service de Pneumologie et Pathologie Professionnelle, Centre Hospitalier Intercommunal de Créteil, Créteil, France.

*These authors contributed equally to the work.
} 


\section{Innovation}

$\mathrm{CO}-\mathrm{RMs}$ have been originally designed as a tool to deliver precise amounts of $\mathrm{CO}$ to cells and tissues to better understand the signaling and physiological effects of this important endogenous gas. Two major classes of CO-RMs have been so far characterized and tested for their pharmacological properties: transition metal carbonyls and boranocarbonates. The emerging chemical diversity, versatility, and reactivity of CORMs with biological systems have clearly opened the possibility of exploiting this novel class of compounds as potential therapeutics. The study presented here reports on the comparative and differential antibacterial activities of these two major classes of CO-RMs, highlighting the importance of certain transition metal carbonyls in rendering $\mathrm{CO}$ more efficacious as bactericidal agent.

oxidase with an ensuing decrease in $\mathrm{O}_{2}$ consumption and increased production of reactive oxygen species (ROS) $(6,13$, $38,46)$. On the other hand, small amounts of $\mathrm{CO}$ can either induce preconditioning through ROS signaling (20) or decrease ROS generation by NADPH oxidase (39), thus playing a role of arbiter in the process of cell survival and death $(7,5$, 42). Since $\mathrm{O}_{2}$ and $\mathrm{CO}$ compete for the same active site in cytochrome c oxidase and NADPH oxidase, the overall effect on oxygen consumption and ROS production will depend strictly on the intracellular concentrations of these two gases, the type of cells and the conditions being considered $(45,18)$.

A recent fundamental advance in the field of $\mathrm{CO}$ research has been the discovery of CO-releasing molecules (CO-RMs), a group of chemicals that serve as carriers for the delivery of controlled amounts of CO in biological systems $(25,9)$. These molecules provide a useful pharmacological tool to exploit the bioactive properties of $\mathrm{CO}$ and at the same time minimize the inherent toxicity of this gas $(17,26,24,23)$. Numerous CORMs have been recently developed possessing different chemical structure and properties as well as different rates of $\mathrm{CO}$ release in cells and tissues $(36,15,3,19,21)$. Essentially, two major groups of CO-RMs have been extensively studied so far: (i) metal carbonyls containing different types of transition metals $(26,24)$; (ii) boranocarbonates that spontaneously release CO under physiological conditions $(27,1,32)$.

In the past 3 years some unprecedented studies revealed that $\mathrm{CO}$ and $\mathrm{CO}-\mathrm{RMs}$ possess potent antimicrobial properties $(29,11,14,28)$. This type of research is of paramount importance because of the major public health problem posed by the increased bacterial resistance to antibiotics currently used to treat infections (16). Among transition metal carbonyls, the best characterized CO-RMs are the lipid-soluble tricarbonyldichlororuthenium(II) dimer (CORM-2) and the water-soluble tricarbonylchloro(glycinato)ruthenium(II) $\left(\mathrm{Ru}(\mathrm{CO})_{3}\right.$ $\mathrm{Cl}$ (glycinate) [CORM-3]) (25, 9). In addition, sodium boranocarbonate (CORM-A1) has been shown so far to be the only nonmetal compound capable of releasing $\mathrm{CO}$ in aqueous solutions (27). Davidge et al. showed that in Escherichia coli under aerobic conditions $\mathrm{CO}$ liberated by CORM-3 binds to the terminal oxidases of the respiratory electron transport chain and inhibits the expression of genes involved in respiration (11). Similarly, Nobre et al. demonstrated that CORM-2 and CORM-3 inhibit the growth of E. coli and Staphyloccocus aureus under both aerobic and anaerobic conditions (29). In a previous work, our group showed that CORM-3 is bacteri- cidal in vitro against Pseudomonas aeruginosa by targeting the respiratory electron transport chain (14). In addition, when administered in vivo, CORM-3 improves the survival of mice subjected to a lethal infection with $P$. aeruginosa (14). The recently developed CO-RMs have been synthesized based on the presence or absence of a metal center, the type of transition metal being used, their solubility in water, and the coordination of ligands of different chemical nature that might modulate the rate of $\mathrm{CO}$ release. Each one of these properties may clearly contribute to the overall reactivity of $\mathrm{CO}$ liberated by CO-RMs toward biological targets. Studying the comparative effects of these different compounds should increase our understanding on the mechanisms of action of CO-RMs on cell function. The aim of the present work was to investigate the effects of CO-RMs on bacterial oxygen consumption and growth of $P$. aeruginosa. Specifically, we used two wellcharacterized ruthenium-containing CO-RMs (CORM-2 and CORM-3), which release CO with a fast kinetic and CORM$\mathrm{A} 1$, which lacks a metal center and liberates $\mathrm{CO}$ with a slow rate. We then compared the effect of these CO-RMs in vitro and in vivo with a newly synthesized CO-releaser, $\left[\mathrm{Me}_{4} \mathrm{~N}\right]\left[\mathrm{Mn}(\mathrm{CO})_{4}(\text { thioacetate })_{2}\right]$ (CORM-371), which contains manganese as transition metal but exhibits a slow kinetic of CO release similar to CORM-A1.

\section{Results}

\section{Detection of CO release from CO-RMs}

The chemical structure of all CO-RMs used in this study are shown in Figure 1. As a first step in studying the antimicrobial action of different CO-RMs, we carefully examined the pattern of $\mathrm{CO}$ release from these compounds using two different techniques: the direct measurement of $\mathrm{CO}$ liberation with an amperometric $\mathrm{CO}$ sensor (Fig. 2A, C) and the conversion of deoxymyoglobin (deoxy-Mb) to carbonmonoxy myoglobin $(\mathrm{MbCO})$ (Fig. 2B, D). Depending on the CO-RM examined and the method used for detecting $\mathrm{CO}$ release two patterns were identified. On one hand, both the $\mathrm{CO}$ electrode (Fig. 2A) and the $\mathrm{Mb}-\mathrm{CO}$ assay (Fig. 2B) showed that CORM-A1 (the boron-

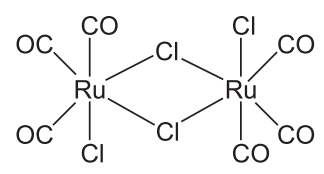

CORM-2

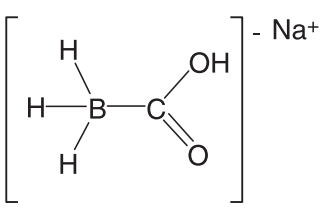

CORM-A1

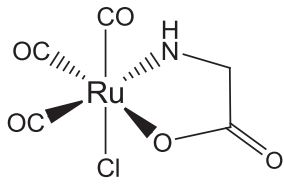

CORM-3



FIG. 1. Chemical structure of CORM-2, CORM-3, CORM371, and CORM-A1. As shown, CORM-2 and CORM-3 contain a ruthenium center, CORM-371 is based on manganese, and CORM-A1 does not contain any transition metal. CORM-A1, sodium boranocarbonate; CORM-2, tricarbonyldichlororuthenium(II) dimer; CORM-3, $\mathrm{Ru}(\mathrm{CO})_{3}$ $\mathrm{Cl}$ (glycinate); CORM-371, $\left[\mathrm{Me}_{4} \mathrm{~N}\right]\left[\mathrm{Mn}(\mathrm{CO})_{4}\right.$ (thioacetate) $\left.{ }_{2}\right]$. 
FIG. 2. Detection of $\mathrm{CO}$ release from CO-RMs: comparison between $\mathrm{CO}$ electrode and myoglobin assay. Left panels. Typical tracings showing the current measured by an amperometric $\mathrm{CO}$ sensor immersed in an aqueous solution at $37^{\circ} \mathrm{C}$ upon addition of $100 \mu \mathrm{M} \mathrm{CO}-$ RMs. Note that while $\mathrm{CO}$ is gradually detected over time from CORM-A1 and CORM371 (A), no CO is measured after addition of either CORM-2 or CORM-3 (C). Right panels. The amount of $\mathrm{MbCO}$ formed over time at $37^{\circ} \mathrm{C}$ was measured after addition of $50 \mu \mathrm{M}$ CO-RMs to a phosphate buffered solution (pH 7.4) containing $50 \mu \mathrm{M}$ deoxymyoglobin. Note that the rate of $\mathrm{CO}$ release from CORM-A1 and CORM-371 (B) is similar (half-life at $20 \mathrm{~min}$ ) and much slower compared with CORM-2 and CORM-3 (D), which release $\mathrm{CO}$ to myoglobin with a half-life of $<1 \mathrm{~min}$. Bars represents the mean $\pm \mathrm{SEM}$ of three experiments. $\mathrm{CO}$, carbon monoxide; $\mathrm{CO}$ RMs, carbon monoxide-releasing molecules; MbCO, carbonmonoxy myoglobin; SEM, standard error of the mean.

based compound) and CORM 371 (the Mn-based compound) liberated $\mathrm{CO}$ with a similar slow rate. The half-life for CORM$\mathrm{A} 1$ and CORM-371 calculated from the formation of $\mathrm{Mb}-\mathrm{CO}$ over time was 16.5 and $20.2 \mathrm{~min}$, respectively. On the other hand, the $\mathrm{Mb}-\mathrm{CO}$ assay confirmed that CORM-2 and CORM3 , both ruthenium-based compounds, released $\mathrm{CO}$ with a very fast rate (Fig. 2D), as previously published by our group $(25,9)$. However, and of major interest, no $\mathrm{CO}$ was detected from CORM-2 and CORM-3 when using the CO electrode (Fig. 2C). These results indicate that certain CO-RMs spontaneously release $\mathrm{CO}$ in solution, whereas others need an interaction with biological components to trigger the release of $\mathrm{CO}(30)$.

\section{Metal-containing CO-RMs but not CORM-A1 exert persistent inhibition of bacterial growth}

Based on previous data showing that $\mathrm{CO}$ mediated the antibacterial effect of CORM-3 (14), we hypothesized that differences in the rates of $\mathrm{CO}$ release could impact the effect of different CO-RMs on bacterial growth. Interestingly, CORM2, CORM-3, and CORM-371 (10-500 $\mu \mathrm{M})$ inhibited bacterial growth during a $20 \mathrm{~h}$ period with substantial inhibition observed already at the lowest concentration examined $(p<0.01$ for each concentration vs. vehicle; Fig. 3A-C). Conversely, the inhibition of bacterial growth by CORM-A1 $(10-500 \mu M)$ was reversible and the duration of this inhibition was concentration dependent. Treatment with CORM-A1 at 10, 100, and $500 \mu M$ delayed bacterial growth for 120,240 , and $470 \mathrm{~min}$, respectively (Fig. 3D). Repeated additions of $100 \mu \mathrm{M}$ CORMA1 to the culture medium every $3 \mathrm{~h}$ during a $6 \mathrm{~h}$ period provided a longer inhibition of bacterial growth than a single initial addition of $300 \mu M$, but bacterial growth inhibition was still reversible (data not shown). In a previous study we showed that the bactericidal effect of CORM-3 was mediated by binding of $\mathrm{CO}$ to $P$. aeruginosa (PAO1) respiratory chain (14). Thus, we analyzed the effect of CORM-2, CORM-3, CORM-371, and CORM-A1 on PAO1 viability (Fig. 4A) and oxygen $\left(\mathrm{O}_{2}\right)$ consumption (Fig. 4B). These experiments required a high bacterial load $\left(5 \times 10^{8} \mathrm{cfu} / \mathrm{ml}\right)$ to reach a level of $\mathrm{O}_{2}$ consumption detectable by the electrode. The results obtained from these experiments are very interesting and informative. First, treatment with CORM-2 and CORM-3 $(100 \mu M)$ induced a similar and significant decrease in $\mathrm{O}_{2}$ consumption and a fast bactericidal effect with bacterial count decreasing from $2 \times 10^{6}$ to 0 within $3 \mathrm{~h}$. Second, although CORM-371 $(100 \mu \mathrm{M})$ decreased $\mathrm{O}_{2}$ consumption in a manner similar to CORM-2 and CORM-3, bacterial count diminished significantly after $2 \mathrm{~h}$ but stopped after $4 \mathrm{~h}$. Third, CORM-A1 $(100 \mu M)$ decreased $\mathrm{O}_{2}$ consumption only temporarily reaching a steady state after 60 min of treatment; moreover, CORM-A1 did not diminish bacterial count. Collectively, these data show that the metal-based CORM-2, CORM-3, and CORM-371 produce a comparable inhibition of bacterial growth and $\mathrm{O}_{2}$ consumption, but the manganese compound (CORM-371) decreases bacterial count less potently than the ones containing ruthenium. CORM-A1, which does not contain a transition metal, elicits a decrease in $\mathrm{O}_{2}$ consumption and bacterial growth that are less pronounced than other CO-RMs and are only temporary. These results suggest that the early inhibition of $\mathrm{O}_{2}$ consumption by $\mathrm{CO}$ released from $\mathrm{CO}-\mathrm{RMs}$ is not the only factor influencing their bactericidal effect. 
A

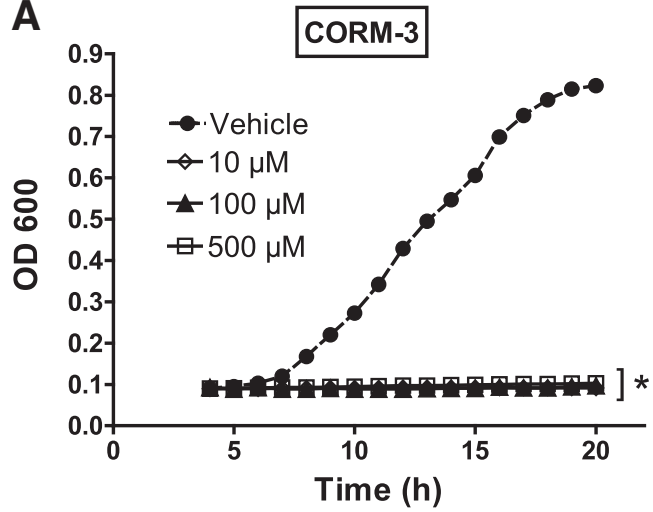

C

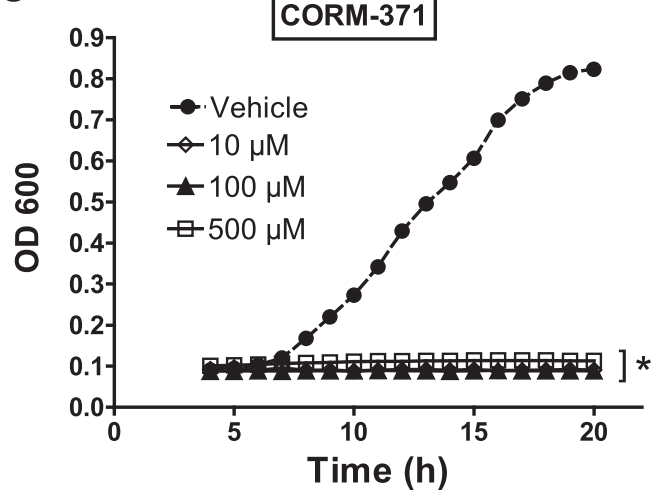

B

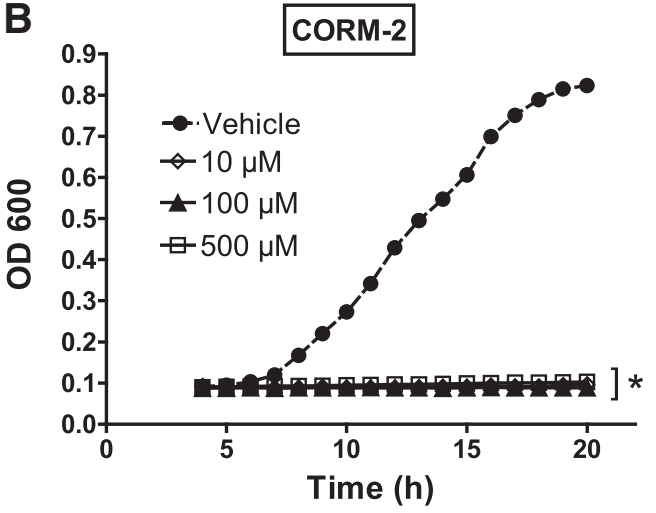

D

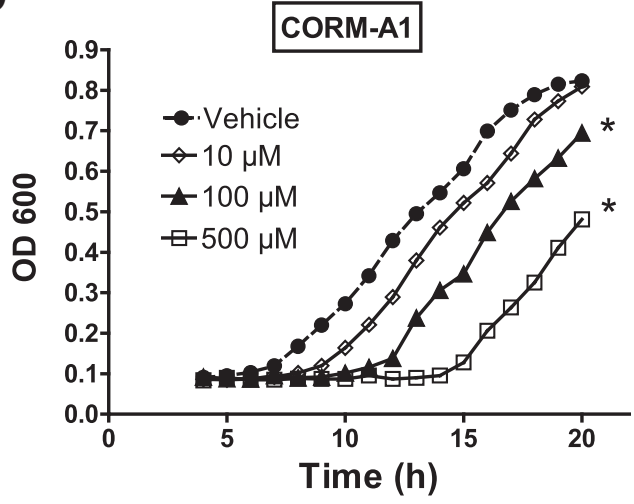

FIG. 3. Effect of CO-RMs on Pseudomonas aeruginosa growth. Bacterial growth was followed for $20 \mathrm{~h}$ after treatment with CO-RMs $(10,100$ and $500 \mu \mathrm{M})$ or vehicle and was assessed by measuring spectrophotometrically the optical density at $600 \mathrm{~nm}$. The initial PAO1 inoculum was $4 \times 10^{6} \mathrm{cfu} / \mathrm{ml}$. The vehicle used was sodium chloride $0.9 \%$ for the water-soluble CORM-3 (A), CORM-371 (C), and CORM-A1 (D) and 0.1\% DMSO for the lipid soluble CORM-2 (B). Curves represent means of 6 independent experiments; error bars are omitted for clarity. ${ }^{*} p<0.05$ versus vehicle. DMSO, dimethyl sulfoxide; PAO1, Pseudomonas aeruginosa.

\section{Effect of ROS production and $\mathrm{N}$-acetylcysteine on CO-RM-mediated bacterial growth}

To investigate whether oxidative stress is involved in the antibacterial effect mediated by CO-RMs, we measured the oxidation of $2^{\prime}, 7^{\prime}$-dichlorofluorescin diacetate (DCFH-DA) as an index of the production of ROS by PAO1 after treatment with the various compounds. We found that none of the CORMs changed ROS production after 30 or $60 \mathrm{~min}$ (see Fig. 5), confirming previous results obtained with CORM-3 (14). The results also exclude oxidative stress as a potential mechanism of bactericidal activity caused by CO-RMs. In the context of oxidative stress, we have recently shown that $N$-acetylcysteine (NAC) and other thiol compounds reverse the effect elicited by CORM-3 on bacterial growth and $\mathrm{O}_{2}$ consumption (14), leading us to hypothesize that NAC interferes with the interaction of $\mathrm{CO}$ liberated from CORM-3 and the cytochromes of the bacterial respiratory chain. Since our present data show that CO-RMs with different chemical properties differentially influence bacterial growth and $\mathrm{O}_{2}$ consumption, we examined the effect of NAC on the modification of bacterial growth induced by CORM-2, CORM-3, CORM-371 and CORM-A1. We found that NAC $(1 \mathrm{mM})$ completely inhibited the anti-bacterial effect of CORM-2 and CORM-3 (Fig. 6A, B), whereas its effect in the presence of CORM-371 was more complex. In fact, NAC did not inhibit bacterial growth induced by $500 \mu \mathrm{M}$ of CORM-371 but partially reversed the inhibition induced by 10 and $100 \mu M$ (Fig. 6C). Finally, NAC did not modify CORM-A1-induced delay in bacterial growth (Fig. 6D).

\section{Concentrations of CO-RMs that are bactericidal and anti-inflammatory do not cause toxicity in eukaryotic cells}

Having demonstrated that CO-RMs exert anti-bacterial activities, we evaluated their anti-inflammatory and toxicity profiles in eukaryotic cells at the concentrations that exhibit bactericidal properties. As previously shown for CORM-2 and CORM-3 $(35,37)$, we found that CORM-371 and CORM-A1 at concentrations between 10 and $100 \mu \mathrm{M}$ are not toxic to macrophages as indicated by preserved cell viability (lactate dehydrogenase [LDH] release) after $24 \mathrm{~h}$ incubation (Fig. 7A). Interestingly, whereas CORM-371 significantly decreased nitrite production in lipopolysaccharide (LPS)-stimualted macrophages, CORM-A1 did not show any anti-inflammatory effect (Fig. 7B, C). In addition, no significant cell toxicity was detected in human lung fibroblasts from both smokers and nonsmokers treated with 10-100 $\mu$ M CO-RMs (Fig. 7D). Thus, it appears that CO-RMs are not cytotoxic in murine and human cells at the range of concentrations that exert anti- 




B

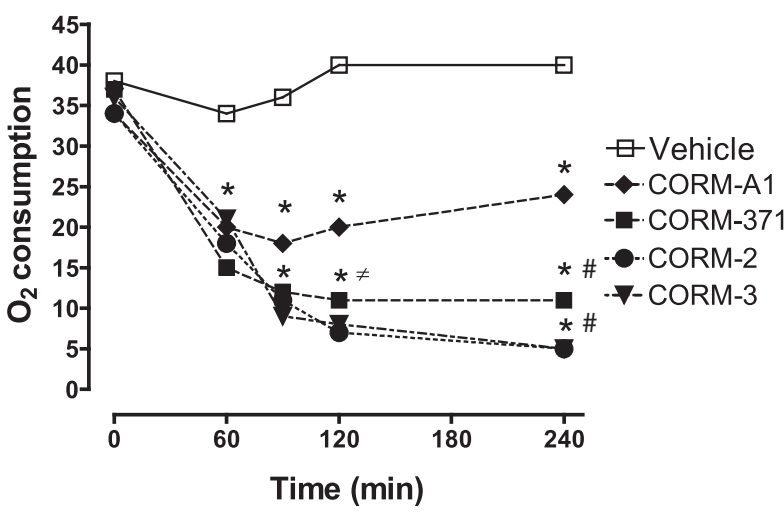

FIG. 4. Effect of CO-RMs on bacterial count and oxygen consumption. (A). Bacterial count on agar plate was measured every hour over a $6 \mathrm{~h}$ period after PAO1 strain $\left(2 \times 10^{6}\right.$ $\mathrm{cfu} / \mathrm{ml}$ ) was treated with $100 \mu \mathrm{M}$ CORM-2, CORM-3, CORM-371, or CORM-A1. ${ }^{*} p<0.05$ versus bacterial count before treatment $(0 \mathrm{~h}$ line). Each curve represents the mean of four independent experiments. (B). Oxygen consumption measured over time during bacterial growth using a Clark type oxygen electrode. PAO1 strain $\left(5 \times 10^{8} \mathrm{cfu} / \mathrm{ml}\right)$ was treated with $100 \mu M$ CORM-2, CORM-3, CORM-371, or CORM-A1 (sodium chloride $0.9 \%$ was used as vehicle in the control group). Measurements were performed at times 0, 10, $60,90,120$, and $240 \mathrm{~min}$ after treatment. Each curve represents the mean of four independent experiments. ${ }^{*} p<0.05$ versus vehicle; ${ }^{*} p<0.05$ versus CORM-A1.

bacterial action. Moreover, metal-containing CO-RMs are more efficacious in their anti-inflammatory and anti-bacterial activity in vitro than nonmetal CO-RMs. To provide readers with a concise picture of the results collected in this study, we summarized in Table 1 the characteristics of CO-RMs, their rates of CO-release, and their effects on bacterial $\mathrm{O}_{2}$ consumption and growth.

\section{Effects of CO-RMs on bacterial infection in vivo}

Among the three CO-RMs tested, only CORM-2 displayed a significant efficacy in a model of bacterial infection. As shown in Figure 8, administration of CORM-2 $(25 \mu \mathrm{mol} / \mathrm{kg})$ significantly prolonged the survival of mice infected with PAO1 at 24, 48, and $72 \mathrm{~h}$ (Fig. 8A), whereas CORM-371 was without effect (Fig. 8B) and CORM-A1 worsen the survival rate already at $24 \mathrm{~h}$ (Fig. $8 \mathrm{C}$ ). These data support previous



FIG. 5. Production of $\mathrm{H}_{2} \mathrm{O}_{2}$ in PAO1 bacteria treated with CO-RMs. The production of $\mathrm{H}_{2} \mathrm{O}_{2}$ in bacteria treated with $100 \mu M$ CORM-2, CORM-3, CORM-371, or CORM-A1 was measured fluorometrically after addition of $2^{\prime}-7^{\prime}-$ dichlorodihydrofluorescein diacetate (see Materials and Methods for details). Sodium chloride $0.9 \%$ (vehicle) and DMSO were used as negative control for CORM-3 and CORM2 , respectively. Each bar represents the mean \pm SEM of six independent experiments. $\mathrm{H}_{2} \mathrm{O}_{2}$, hydrogen peroxide.

results obtained by our group showing that another ruthenium-based carbonyl complex (CORM-3) exerts bactericidal activity against $P$. aeruginosa and improves survival in an animal model of bacteraemia (14).

\section{Discussion}

The results of the present study reveal a differential antibacterial effect mediated by CO-RMs which depends on the specific chemical nature of the compounds used. Indeed, the CO-RMs tested not only exhibited a different chemical structure but were also selected based on the rate of $\mathrm{CO}$ release and the presence or absence of specific transition metals. CORM-2 and CORM-3 contain ruthenium and are defined as fast $\mathrm{CO}$ releasers since $\mathrm{CO}$ liberation occurs within $1 \mathrm{~min}$ after their addition to biological systems [present results and $(25,9,24)]$. These two compounds only differ by their solubility, in DMSO for CORM-2 and in water for CORM-3. In contrast, CORM-A1 does not contain any transition metal but boron, and spontaneously releases $\mathrm{CO}$ in aqueous solution with a half-life of approximately $21 \mathrm{~min}$ under physiological conditions $\left(37^{\circ} \mathrm{C}\right.$, pH 7.4) (27). In this study we also tested a new compound, CORM-371, which is instrumental for comparison with the others as it contains manganese (therefore falling into the category of transition metal carbonyls) but releases $\mathrm{CO}$ with a kinetic very similar to CORM-A1. We found that CORM-2 and CORM-3 exerted inhibition of bacterial growth, which was accompanied by an intense bactericidal effect and a persistent decrease in $\mathrm{O}_{2}$ consumption. These findings confirm our previously published results on the antimicrobial effects of CORM-3 on $P$. aeuroginosa (14) and reports by others on the effects of CORM-2 and CORM-3 on E. coli and S. aureus (11, 29). We also observed an anti-bacterial activity of CORM-371 and CORM-A1, although with a different profile. CORM-A1 inhibited $\mathrm{O}_{2}$ consumption less profoundly than CORM-2 and CORM-3 and only delayed the initiation of bacterial growth. In addition, CORM-A1 had no bactericidal properties but acted more like a bacteriostatic agent. Interestingly, this effect is akin to that elicited by $\mathrm{CO}$ gas as reported in a previous work published by our group (14). Of note is that the novel 

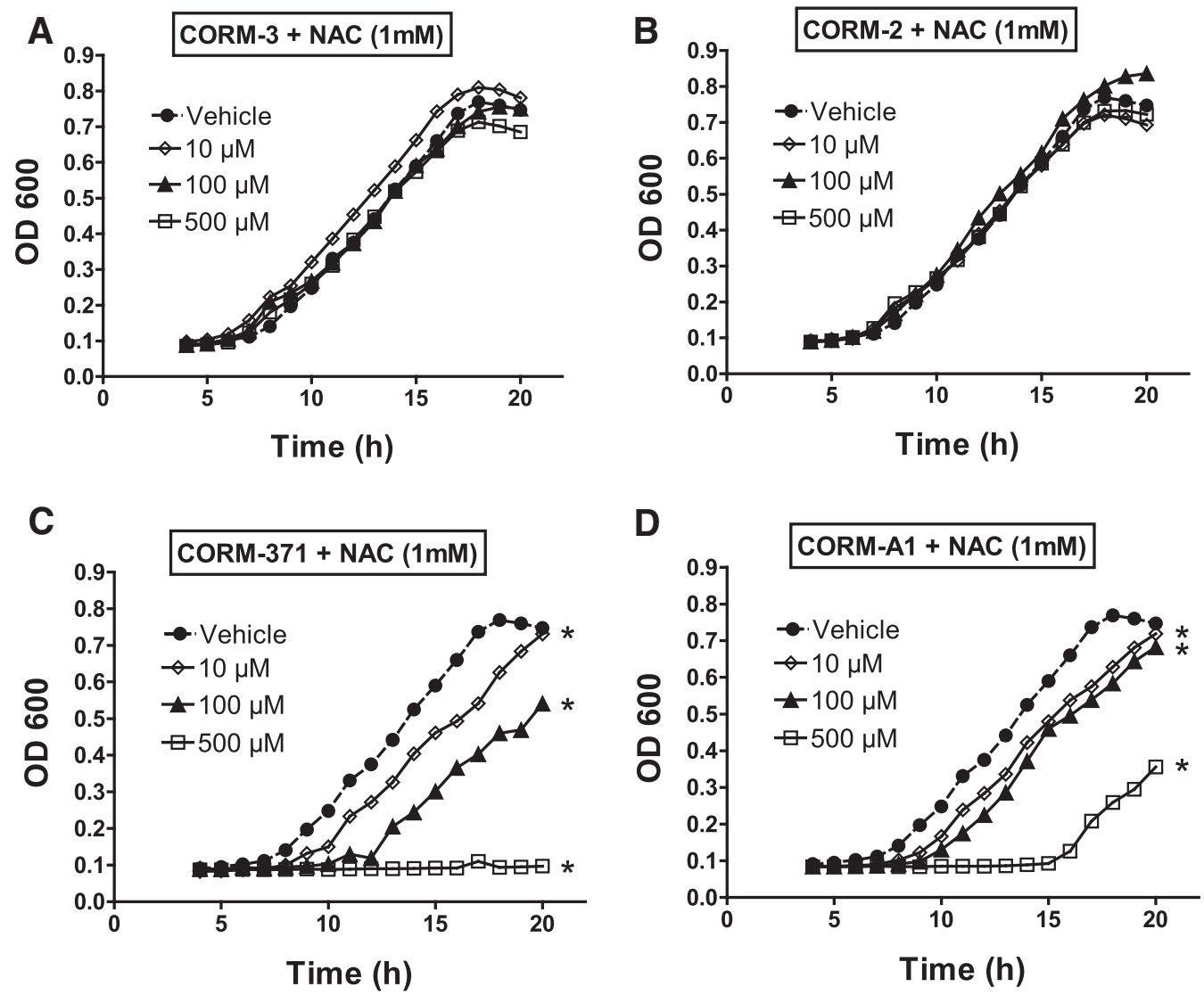

FIG. 6. Effect of CO-RMs on PAO1 growth in the presence of NAC. Bacterial growth was followed for $20 \mathrm{~h}$ after treatment with CO-RMs $(10,100$ and $500 \mu \mathrm{M})$ or vehicle in the presence of $1 \mathrm{mM}$ NAC and was assessed by measuring spectrophotometrically the optical density at $600 \mathrm{~nm}$. Initial PAO1 inoculum was $4 \times 10^{6} \mathrm{cfu} / \mathrm{ml}$. The vehicle used was sodium chloride $0.9 \%$ for the water-soluble CORM-3 (A), CORM-371 (C), and CORM-A1 (D) and 0.1\% DMSO for the lipid soluble CORM-2 (B). Curves represent means of six independent experiments; error bars are omitted for clarity. ${ }^{*} p<0.05$ versus vehicle. NAC, $N$-acetylcysteine.

manganese-containing CORM-371 is a slow CO releaser with a profile comparable to that of CORM-A1. However, the antibacterial potency of CORM-371 was found to be intermediate between the ruthenium-based compounds (CORM-2 and CORM-3) and CORM-A1 since CORM-371 caused a profound inhibition of $\mathrm{O}_{2}$ consumption and bacterial growth but exerted a bactericidal effect less intense than CORM-2 or CORM-3.

Thus, the fact that CORM-371 and CORM-A1 have a similar rate of CO release but CORM-A1 only exerts a bacteriostatic effect strongly suggests that the kinetic of $\mathrm{CO}$ liberation from CO-RMs is not crucial to manifest their antibacterial effects. Rather, combined with the results obtained with the ruthenium based CORM-2 and CORM-3, which rapidly abolished bacterial growth in vitro, it appears that the presence of a metal center and the nature of transition metal in general play a more important role in the antibacterial activity exerted by CO-RMs. In our precedent work, we established that ruthenium per se did not posses any proper anti-bacterial activity (14). However, our data suggest also that the nature of the metal center cannot totally explain the effects of CO-RMs on $\mathrm{O}_{2}$ consumption. Although we recently hypothesized that the bactericidal effect of CORM-3 was mainly due to its ability to decrease $\mathrm{O}_{2}$ consumption (14), the current expanded study suggests otherwise. In fact, we found that the rutheniumbased compounds and the manganese-based CORM-371 similarly decreased bacterial $\mathrm{O}_{2}$ consumption but differen- tially affected bacterial count. Thus, the direct inhibition of bacterial $\mathrm{O}_{2}$ consumption by CO-RMs does not justify the antibacterial effect of these agents. This hypothesis is also supported by previous works showing that both CORM-2 and CORM-3 inhibit the growth of E. coli under anaerobic condition $(11,29)$. Other interesting mechanisms have been proposed to explain the antibacterial effect of CO-RMs. Davidge et al. showed that in E. coli treated with CORM-3 transcriptor regulators other than the ones involved in $\mathrm{O}_{2}$ consumption or sensing (ArcA, CRP, Fis, FNR, Fur, BaeR, CpxR, and IHF) could be a target of CO (11). Another report provided data on a microarray analysis of E. coli treated with CORM-2 and showed up-regulation of genes involved in sulfur metabolism, such as tau $A B C, \operatorname{ssu} A D, \operatorname{cys} W A$, and $s b p$, and in methionine metabolism, like the gene clusters metNI and metBLF (28). In the same study it was demonstrated that E. coli mutants lacking genes involved in methionine biosynthesis had an increased sensitivity to CORM-2. This particular result suggests that the thiol-containing amino-acid methionine could play a protective role in bacteria against the toxic activities of CORM-2. This intriguing finding is in line with the results of our previous work showing that supplementation of growth medium with thiol-containing NAC or reduced glutathione inhibited the antibacterial effect mediated by CORM-3 but had no effect on the conversion of deoxy-Mb to $\mathrm{MbCO}(14)$. In the present study we confirm that the anti- 
A

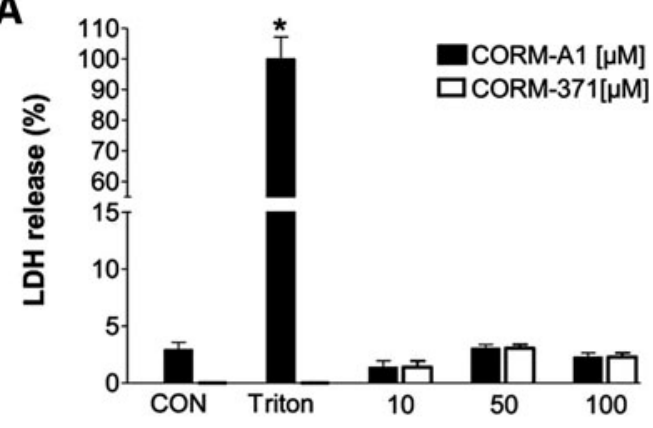

B

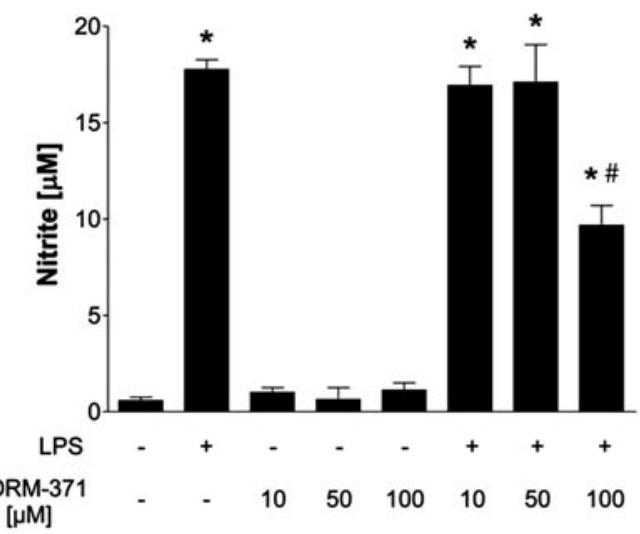

D

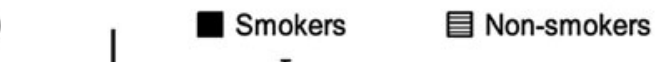

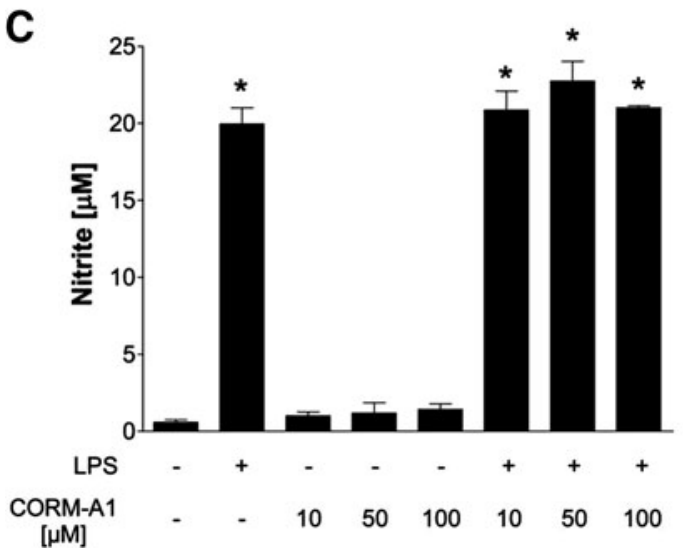

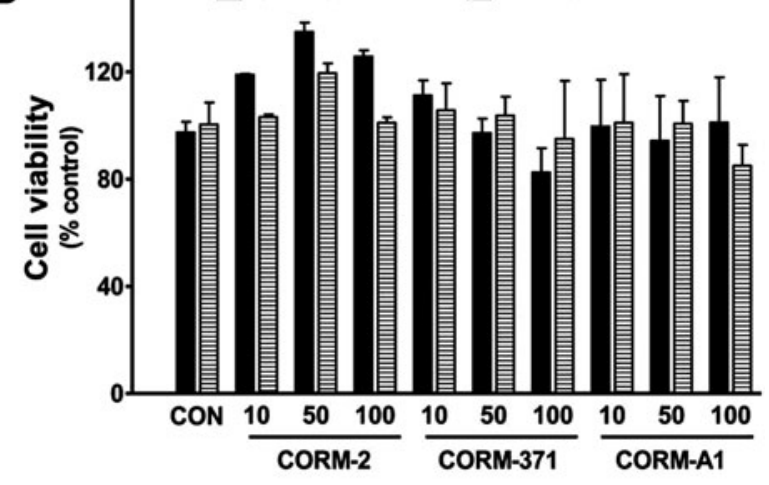

FIG. 7. Cytotoxicity and anti-inflammatory profiles of CORM-A1 and CORM-371 in RAW 264.7 macrophages and human lung fibroblasts. (A) LDH, an index of cell injury, was measured in the medium after treating macrophages for $24 \mathrm{~h}$ with CORM-A1 (black bars) or CORM-371 (gray bars). Cells were incubated for $24 \mathrm{~h}$ with CO-RMs $(0-100 \mu M)$. The data $(n=6)$ are expressed as a percentage of cell toxicity caused by triton (1\%) (positive control). ${ }^{*} p<0.05$ versus control; $\mathbf{B}$ and $\mathbf{C}$. Nitrite production in macrophages challenged for $24 \mathrm{~h}$ with $1 \mu \mathrm{g} / \mathrm{ml}$ LPS alone or LPS in the presence of CORM-371 (B) or CORMA1 (C). Bars represent the mean of six independent experiments (mean \pm SEM). ${ }^{*} p<0.05$ versus no treatment (control); $p<0.05$ versus LPS. (D) Cytotoxicity (MTT assay) in human lung fibroblasts collected from healthy subjects and smokers was measured in cells treated for $24 \mathrm{~h}$ with CO-RMs $(0-100 \mu M)$. The data $(n=6)$ are expressed as \% of control $(100 \%$ viability). LDH, lactate dehydrogenase; LPS, lipopolysaccharide.

bacterial effects of metal-containing CO-RMs (CORM-2, CORM-3, and CORM-371) but not CORM-A1 was reversed by the presence of NAC in the growth medium. These data point toward an interplay between the metal center of a given CO-RM, the inhibitory capacities of metal carbonyls on bacterial growth and the presence of thiol-containing aminoacids in bacteria. Although little is known about the role of thiols in bacterial targets that are responsive to $\mathrm{CO}$, the importance of cysteine residues in modulating a thiol/disulfide redox switch that controls the affinity of heme and CO for large conductance calcium-activated potassium channels $\left(\mathrm{BK}_{\mathrm{Ca}}\right)$ has recently been proposed (44). Apart from altering the interaction of sensitive cysteines with iron-heme centers, the presence of high concentrations of thiols as in our experimental setting may favor a very rapid release of $\mathrm{CO}$ from transition-metal carbonyls, thus preventing the gas to reach the intracellular milieu and evoke its effect intracellularly (19). Nevertheless, the nature of this important interplay between intracellular and extracellular thiols and $\mathrm{CO}$ in their interaction with critical metal centers in functional proteins sensitive to $\mathrm{CO}$ deserves further deep investigation.

Thus, the results presented here strongly suggest that the rate of $\mathrm{CO}$ liberation by CO-RMs is not the only component affecting the growth of Pseudomonas, but a more important role is played by the metal center in maximizing the antibacterial effect of $\mathrm{CO}$. We emphasize that ruthenium-based compounds (CORM-2 and CORM-3), which similarly affect bacterial growth, cell viability, and $\mathrm{O}_{2}$ consumption, elicit a very fast carbonylation of myoglobin, but no $\mathrm{CO}$ release is detected using a $\mathrm{CO}$ electrode. This suggests either a direct transfer of CO from CO-RM to its potential target and/or the need of specific aminoacid in proteins (in this case myoglobin), which favors the liberation of CO. We did not observe any toxicity of CORM-371 and CORM-A1 against eukaryotic cells and this is in line with previous works showing similar results using CORM-2 and CORM-3 $(14,37)$. The high sensitivity of $P$. aeruginosa toward CO-RMs as compared with macrophages may be due to a greater accessibility of $\mathrm{CO}$ to targets in bacteria. The data obtained in vivo provide more instructive information as among the CO-RMs tested only CORM-2 was significantly effective in prolonging the survival rate of mice infected with $P$. aeruginosa. First of all, this is in line with previous results showing that CORM-2 reduces endotoxemia and increases survival in infected HO-1-deficient mice (40). Moreover, our present results supports our previous findings on the in vivo antibacterial effects of CORM- 
Table 1. Chemical Features of Carbon Monoxide-Releasing Molecules, Their Rates of Carbon Monoxide-Release Measured with Two Different Assays and Their Effects on Bacterial $\mathrm{O}_{2}$ Consumption and Growth

\begin{tabular}{|c|c|c|c|c|c|c|c|}
\hline \multirow[b]{2}{*}{ Compound } & \multirow[b]{2}{*}{$\begin{array}{l}\text { Metal } \\
\text { center }\end{array}$} & \multicolumn{2}{|c|}{ Rate of $\mathrm{CO}$ release } & \multirow[b]{2}{*}{$\begin{array}{c}\mathrm{O}_{2} \\
\text { consumption }\end{array}$} & \multirow[b]{2}{*}{$\begin{array}{l}\text { Bacterial } \\
\text { growth }\end{array}$} & \multirow[b]{2}{*}{$\begin{array}{c}\text { Bacterial } \\
\text { count }\end{array}$} & \multirow[b]{2}{*}{$\begin{array}{c}\text { Effect of } \\
\mathrm{N} \text {-acetylcysteine }\end{array}$} \\
\hline & & $\begin{array}{c}\text { CO } \\
\text { electrode }\end{array}$ & $\begin{array}{c}\text { Myoglobin } \\
\text { assay }\end{array}$ & & & & \\
\hline CORM-2 & Ruthenium & Not detected & Fast & Profound decrease & Inhibition & Total decrease & Total \\
\hline CORM-3 & Ruthenium & Not detected & Fast & Profound decrease & Inhibition & Total decrease & Total \\
\hline CORM-371 & Manganese & Slow & Slow & Profound decrease & Inhibition & Partial decrease & Partial \\
\hline CORM-A1 & None & Slow & Slow & Mild decrease & $\begin{array}{l}\text { Transient } \\
\text { inhibition }\end{array}$ & No decrease & None \\
\hline
\end{tabular}


FIG. 8. In vivo effects of CO-RMs against PAO1 bacterial infection. Kaplan-Meier curves representing the survival of $\mathrm{BALB} / \mathrm{c}$ mice subjected to PAO1 bacteremia. Five minutes after bacterial challenge, mice ( $n=6$ per group) were treated with a single intraperitoneal injection of $25 \mu \mathrm{mol} / \mathrm{kg}$ CORM2 (A), CORM-371 (B), or CORM-A1 (C). Control groups received vehicle that was either saline in case of the watersoluble CORM-371 and CORM-A1 or DMSO (1\%) in the case of CORM-2. Survival rate was evaluated every $24 \mathrm{~h}$. Logrank test. ${ }^{*} p<0.05$ versus vehicle group.
3 (14), which profile of CO release is the same as CORM-2 when tested with the $\mathrm{CO}$ electrode and the myoglobin assay. We must remember that in vivo both CORM-2 and CORM-3 do not lead to an increase in carbonmonoxy hemoglobin but their ability to transfer CO more effectively to targeted tissues and elicit a pharmacological effect toward a given pathological state is now supported by several studies using in vivo models of disease $(41,22,12,42)$. In the case of CORM-2, liposolubility of this compound may also affect its efficacy compared with the water-soluble CORM-A1 and CORM-371 $(3716,4189)$. Thus, the fact that CORM-2 is the only CO-RM to be effective in vivo against bacterial infection indicate that the specific design of CO-RMs capable of transferring CO directly to a target within a cell (trans-carbonylation) may lead to more effective therapeutic agents based on CO delivery in mammals. In addition, the type of metal that carries $\mathrm{CO}$ to the target may also be crucial in eliciting a specific biological action. Indeed, it is interesting to note that terpyridine ruthenium(II) complexes have been shown to exhibit a very good activity against $P$. aeruginosa and other pathogens (4) indicating that a concerted action between this metal and $\mathrm{CO}$ in the bactericidal effect of CORM-2 and CORM-3 observed in vivo cannot be excluded a priori.

In conclusion, we report here that certain transition metal carbonyls are effective in suppressing $P$. aeruginosa growth and could represent an interesting new chemical scaffold in anti-infective research. This study is the first to indicate that the anti-microbial activities of CO-RMs, particularly CORM-2 and CORM-3, cannot be explained solely by their CO releasing properties since the effects are mediated by a complex network involving $\mathrm{CO}$ liberation, the presence of a metal center that favors $\mathrm{CO}$ targeting bacteria and the interaction between CO-RMs and their intracellular target(s).

\section{Materials and Methods}

\section{Reagents}

NAC was obtained from Sigma-Aldrich. DCFH-DA was obtained from Molecular Probes. CORM-2 was purchased from Sigma Aldrich. CORM-3 and $\mathrm{Na}\left[\mathrm{H}_{3} \mathrm{BCO}_{2} \mathrm{H}\right]$ or CORMA1 were synthesized as previously described $(9,27)$. The novel manganese-containing compound, CORM-371, was prepared as reported below.

\section{Preparation of CORM-371}

One hundred fifty milligrams $(0.436 \mathrm{mmol})$ of $\mathrm{Mn}(\mathrm{CO})_{5}$ $\left(\mathrm{SO}_{3} \mathrm{CF}_{3}\right)(12)$ and $128 \mathrm{mg}(0.857 \mathrm{mmol})$ of $\left[\mathrm{Me}_{4} \mathrm{~N}\right][$ thioacetate] 
were stirred in $8 \mathrm{ml}$ of dry tetrahydrofurane and $2 \mathrm{ml}$ of methanol, under argon at $50-55^{\circ} \mathrm{C}$ for $4.5-5 \mathrm{~h}$. During this time the color of the solution went a little darker yellow/ orange. After this, the solvent was removed on rotary evaporator to give a yellow/orange semi-solid residue. This was crystallized from dichloromethane/diethyl ether at $-18^{\circ} \mathrm{C}$ to give $91 \mathrm{mg}$ of a yellow crystalline product (yield $=55.7 \%$ ).

\section{Bacterial strain and growth conditions}

P. aeruginosa (PAO1, American Tissue Culture Collection 15692) was grown aerobically for $24 \mathrm{~h}$ at $37^{\circ} \mathrm{C}$ in Luria-Bertani (LB) medium and then washed twice in $\mathrm{NaCl} 0.9 \%$ before the experiments. The procedures of growth were the same as previously published by our group (14). Experiments were performed aerobically at $37^{\circ} \mathrm{C}$ in minimal M9 medium $\left(\mathrm{Na}_{2} \mathrm{HPO}_{4} 6 \mathrm{~g} / \mathrm{l}, \mathrm{KH}_{2} \mathrm{PO}_{4} 3 \mathrm{~g} / \mathrm{l}, \mathrm{NaCl} 0.5 \mathrm{~g} / \mathrm{l}, \mathrm{NH}_{4} \mathrm{Cl} 1 \mathrm{~g} / \mathrm{l}\right.$, and $\mathrm{MgSO}_{4} .7 \mathrm{H}_{2} \mathrm{O} 0.25 \mathrm{~g} / \mathrm{l}$ ) containing $2 \mathrm{~g} / 1$ glucose. We used an initial bacterial concentration of $4 \times 10^{6} \mathrm{cfu} / \mathrm{ml}$. PAO1 growth was determined by measuring the optical density at $600 \mathrm{~nm}$ each $10 \mathrm{~min}$ for $20 \mathrm{~h}$ in 96 -well plates using $300 \mu \mathrm{l}$ of medium for each condition. The number of viable cells (bacterial count) was evaluated by measuring the colony-forming unit $(\mathrm{cfu} / \mathrm{ml})$ after plating serial dilutions of the various cultures onto LB agar plates. CO-RMs were added to the growth medium at the concentrations indicated and viability assessed at different times of growth.

\section{Measurement of oxygen consumption}

Oxygen consumption was measured at $37^{\circ} \mathrm{C}$ under agitation using a Clark-type electrode (14). Bacteria $\left(5 \times 10^{8} \mathrm{cfu} / \mathrm{ml}\right)$ were incubated in $1 \mathrm{ml}$ of a respiration buffer containing $100 \mathrm{mM} \mathrm{KCl}, 50 \mathrm{mM}$ sucrose, $10 \mathrm{mM}$ HEPES, and $5 \mathrm{mM}$ $\mathrm{KH}_{2} \mathrm{PO}_{4}, \mathrm{pH} 7.4$, at $37^{\circ} \mathrm{C}$. Respiration was initiated by addition of glucose $(2 \mathrm{~g} / \mathrm{l})$.

\section{Measurement of ROS production by the DCFH-DA assay}

The formation of ROS was measured by oxidation of DCFH-DA into $2^{\prime}, 7^{\prime}$-dichlorofluorescin (DCF). Bacteria were incubated for $60 \mathrm{~min}$ with $20 \mu \mathrm{M}$ DCFH-DA, then centrifuged, and washed twice in Hanks' balanced salt solution (HBSS). Bacteria $\left(2 \times 10^{7} \mathrm{cfu} / \mathrm{ml}\right)$ re-suspended in HBSS were treated with the different CO-RMs $(100 \mu M)$ or vehicle. ROS produced in bacteria lead to oxidation of DCFH, yielding the fluorescent product DCF measured fluorometrically at $520 \mathrm{~nm}$ after excitation at $480 \mathrm{~nm}$ (34).

\section{Detection of $\mathrm{CO}$ release from CO-RMs using a myoglobin assay}

The release of $\mathrm{CO}$ from CO-RMs was assessed spectrophotometrically by measuring the conversion of deoxy-Mb to $\mathrm{MbCO}$ as previously reported $(25,9)$. A small aliquot of concentrated CO-RM solution was added to $1 \mathrm{ml}$ deoxy-Mb solution in phosphate buffer (final concentrations: CO-RM= $50 \mu \mathrm{M}$; deoxy-Mb $=53 \mu \mathrm{M}$ ), and changes in the $\mathrm{Mb}$ spectra were recorded over time. The amount of $\mathrm{MbCO}$ formed was quantified by measuring the absorbance at $540 \mathrm{~nm}$. Before the addition of CO-RMs, $500 \mu \mathrm{l}$ of mineral oil (Sigma Aldrich) was added on top of the aqueous solution containing $\mathrm{Mb}$ to prevent $\mathrm{CO}$ escaping and the myoglobin becoming oxygenated.

\section{Detection of CO release from CO-RMs using an amperometric $\mathrm{CO}$ sensor}

The spontaneous release of $\mathrm{CO}$ from the selected CO-RMs was measured using a CO-sensitive electrode as previously described (27). This CO electrode (World Precision Instrument) is a membrane-covered amperometric sensor that has been designed on a basic operating principle similar to the nitric oxide (NO) sensor. The CO sensor can be connected to the WPI ISO-NO Mark II meter for detection of the current signals providing that the poise potential is set to a different value ( $900 \mathrm{mV}$ for $\mathrm{CO}$ as opposed to $860 \mathrm{mV}$ for NO). Briefly, CO diffuses through the gas permeable membrane and is then oxidized to $\mathrm{CO}_{2}$ on the working electrode. This oxidation will create a current whose magnitude can be related directly to the concentration of $\mathrm{CO}$ in solution. The electrode was immersed into distilled water containing $0.1 \mathrm{M}$ phosphate buffer $(\mathrm{pH}=7.4)$ and equilibrated for $30 \mathrm{~min}$ before addition of CO-RMs $(100 \mu \mathrm{M})$. The experiments were conducted at $37^{\circ} \mathrm{C}$ and the solutions were maintained at the desired temperature using a Grant W6 thermostat.

\section{Assessment of cell viability}

Murine RAW264.7 monocyte macrophages were purchased from the European Collection of Cell Cultures (Salisbury) and cultured in Dulbecco's modified Eagle's medium supplemented with $10 \%$ fetal bovine serum, $2 \mathrm{mM}$ L-glutamine, 100 units $\mathrm{ml}^{-1}$ penicillin, and $0.1 \mathrm{mg} \mathrm{ml}^{-1}$ streptomycin. Cultures were maintained at $37^{\circ} \mathrm{C}$ in a $5 \% \mathrm{CO}_{2}$ humidified atmosphere and experiments were conducted on cells at approximately $80 \%-90 \%$ confluence. Macrophages were exposed for $24 \mathrm{~h}$ to different concentrations of CO-RMs and LDH activity was measured as an index of cell damage using a commercially available assay kit (Roche) according to manufacturer's instructions. Human lung fibroblasts were collected and cultured as previously described (2). Cells were also exposed to different concentrations of CO-RMs for $24 \mathrm{~h}$ and an MTT assay was used at the end to assess the extent of cytotoxicity.

\section{Nitrite assay}

Nitrite production in macrophages stimulated with LPS was determined using the Griess method (35). The measurement of this parameter is indicative of NO production and widely accepted as a marker of inflammation. Macrophages were exposed to LPS $(1 \mu \mathrm{g} / \mathrm{ml})$ for $24 \mathrm{~h}$ in the presence or absence of CO-RMs $(10,50$, and $100 \mu \mathrm{M})$ and nitrite levels were determined at the end of the incubation. Briefly, the medium from treated cells cultured in 24-well plates was removed and placed into a 96-well plate ( $50 \mu \mathrm{l}$ per well). The Griess reagent was added to each well to begin the reaction, the plate was shaken for $10 \mathrm{~min}$, and the absorbance read at $550 \mathrm{~nm}$ on a Molecular Devices VERSAmax plate reader. The nitrite level in each sample was calculated from a standard curve generated with sodium nitrite (0-300 $\mu \mathrm{M}$ in cell culture medium).

\section{In vivo model of bacterial infection}

A mouse model of bacterial infection was used as previously described by us (14). Briefly, bacteremia was obtained by an intraperitoneal injection of $2 \times 10^{7}$ bacteria (PAO1) in $\mathrm{BALB} / \mathrm{c}$ mice ( 7 to 8 weeks old, 20 to $25 \mathrm{~g}$ from Janvier). Mice 
were then treated with $25 \mu \mathrm{mol} / \mathrm{kg} \mathrm{CO}-\mathrm{RM}$ or vehicle administered intraperitoneally $5 \mathrm{~min}$ after bacterial challenge. The dose of for each CO-RM was selected in agreement with previous in vivo studies showing a therapeutic effect of CORM-3 (14). The survival rate was evaluated every $24 \mathrm{~h}$.

\section{Statistical analysis}

Data are expressed as mean \pm standard error of the mean. For comparisons between two groups, we used two-tailed nonparametric Mann-Whitney $U$ analysis. For comparison among more than two groups and multiple comparisons, we used the nonparametric Kruskal-Wallis test with the Dunn's post test. The number of samples per group $(n)$ is specified in Results or in the figure legend. Statistical significance was accepted at $p<0.05$.

\section{Acknowledgments}

Roberto Motterlini was supported by a Visiting Professorship at the Université Paris Est, Faculté de Médecine, 94010 Creteil.

\section{Author Disclosure Statement}

Roberto Motterlini and Brian Mann have financial interests with Alfama, Inc. (Lisbon, Portugal).

\section{References}

1. Alberto R and Motterlini R. Chemistry and biological activities of CO-releasing molecules (CORMs) and transition metal complexes. Dalton Trans 1651-1660, 2007.

2. Amara N, Goven D, Prost F, Muloway R, Crestani B, and Boczkowski J. NOX4/NADPH oxidase expression is increased in pulmonary fibroblasts from patients with idiopathic pulmonary fibrosis and mediates TGFbeta1-induced fibroblast differentiation into myofibroblasts. Thorax 65: 733-738, 2010.

3. Andre L, Boissiere J, Reboul C, Perrier R, Zalvidea S, Meyer G, Thireau J, Tanguy S, Bideaux P, Hayot M, Boucher F, Obert $\mathrm{P}$, Cazorla $\mathrm{O}$, and Richard S. Carbon monoxide pollution promotes cardiac remodeling and ventricular arrhythmia in healthy rats. Am J Respir Crit Care Med 181: 587-595, 2010.

4. Anthonysamy A, Balasubramanian S, Shanmugaiah V, and Mathivanan N. Synthesis, characterization and electrochemistry of $4^{\prime}$-functionalized $2,2^{\prime}: 6^{\prime}, 2^{\prime \prime}$-terpyridine ruthenium(II) complexes and their biological activity. Dalton Trans 2136-2143, 2008.

5. Bilban M, Haschemi A, Wegiel B, Chin BY, Wagner O, and Otterbein LE. Heme oxygenase and carbon monoxide initiate homeostatic signaling. J Mol Med 86: 267-279, 2008.

6. Boczkowski J, Poderoso JJ, and Motterlini R. CO-metal interaction: vital signaling from a lethal gas. Trends Biochem Sci 31: 614-621, 2006.

7. Chin BY and Otterbein LE. Carbon monoxide is a poison... to microbes! CO as a bactericidal molecule. Curr Opin Pharmacol 9: 490-500, 2009.

8. Clark JE, Green CJ, and Motterlini R. Involvement of the heme oxygenase-carbon monoxide pathway in keratinocyte proliferation. Biochem Biophys Res Commun 241: 215-220, 1997.

9. Clark JE, Naughton P, Shurey S, Green CJ, Johnson TR, Mann BE, Foresti R, and Motterlini R. Cardioprotective actions by a water-soluble carbon monoxide-releasing molecule. Circ Res 93: e2-e8, 2003.

10. Davidge KS, Motterlini R, Mann BE, Wilson JL, and Poole RK. Carbon monoxide in biology and microbiology: sur- prising roles for the "Detroit Perfume." Adv Microbiol Physiol 56: 85-167, 2009.

11. Davidge KS, Sanguinetti G, Yee CH, Cox AG, McLeod CW, Monk CE, Mann BE, Motterlini R, and Poole RK. Carbon monoxide-releasing antibacterial molecules target respiration and global transcriptional regulators. J Biol Chem 284: 4516-4524, 2009.

12. De Backer O, Elinck E, Blanckaert B, Leybaert L, Motterlini $\mathrm{R}$, and Lefebvre RA. Water-soluble CO-releasing molecules (CO-RMs) reduce the development of postoperative ileus via modulation of MAPK/HO-1 signaling and reduction of oxidative stress. Gut 58: 347-356, 2009.

13. Desmard M, Boczkowski J, Poderoso J, and Motterlini R. Mitochondrial and cellular heme-dependent proteins as targets for the bioactive function of the heme oxygenase/carbon monoxide system. Antioxid Redox Signal 9: 2139-2155, 2007.

14. Desmard M, Davidge KS, Bouvet O, Morin D, Roux D, Foresti R, Ricard JD, Denamur E, Poole RK, Montravers P, Motterlini R, and Boczkowski J. A carbon monoxide-releasing molecule (CORM-3) exerts bactericidal activity against Pseudomonas aeruginosa and improves survival in an animal model of bacteraemia. FASEB J 23: 1023-1031, 2009.

15. Fairlamb IJ, Lynam JM, Moulton BE, Taylor IE, Duhme-Klair AK, Sawle P, and Motterlini R. h(1)-2-Pyrone metal carbonyl complexes as CO-releasing molecules (CO-RMs): a delicate balance between stability and CO liberation. Dalton Trans 3603-3605, 2007.

16. Flamm RK, Weaver MK, Thornsberry C, Jones ME, Karlowsky JA, and Sahm DF. Factors associated with relative rates of antibiotic resistance in Pseudomonas aeruginosa isolates tested in clinical laboratories in the United States from 1999 to 2002. Antimicrob Agents Chemother 48: 2431-2436, 2004.

17. Foresti R, Bani-Hani MG, and Motterlini R. Use of carbon monoxide as a therapeutic agent: promises and challenges. Intensive Care Med 34: 649-658, 2008.

18. Gorman D, Drewry A, Huang YL, and Sames C. The clinical toxicology of carbon monoxide. Toxicology 187: 25-38, 2003.

19. Hasegawa U, van der Vlies AJ, Simeoni E, Wandrey C, and Hubbell JA. Carbon monoxide-releasing micelles for immunotherapy. J Am Chem Soc 132: 18273-18280, 2010.

20. Kondo-Nakamura M, Shintani-Ishida K, Uemura $K$, and Yoshida K. Brief exposure to carbon monoxide preconditions cardiomyogenic cells against apoptosis in ischemiareperfusion. Biochem Biophys Res Commun 393: 449-454, 2010.

21. Kretschmer R, Gessner G, Gorls H, Heinemann SH, and Westerhausen M. Dicarbonyl-bis(cysteamine)iron(II): a light induced carbon monoxide releasing molecule based on iron (CORM-S1). J Inorg Biochem 105: 6-9, 2011.

22. Lancel S, Hassoun SM, Favory R, Decoster B, Motterlini R, and Neviere R. Carbon monoxide rescues mice from lethal sepsis by supporting mitochondrial energetic metabolism and activating mitochondrial biogenesis. J Pharmacol Exp Ther 1329: 641-648, 2009.

23. Mann BE and Motterlini R. CO and NO in medicine. Chem Commun 41: 4208, 2007.

24. Motterlini R. Carbon monoxide-releasing molecules (CORMs): vasodilatory, anti-ischemic and anti-inflammatory activities. Biochem Soc Trans 35: 1142-1146, 2007.

25. Motterlini R, Clark JE, Foresti R, Sarathchandra P, Mann BE, and Green CJ. Carbon monoxide-releasing molecules: characterization of biochemical and vascular activities. Circ Res 90: E17-E24, 2002.

26. Motterlini $\mathrm{R}$ and Otterbein LE. Therapeutic potential of carbon monoxide. Nat Rev Drug Discov 9: 728-743, 2010. 
27. Motterlini R, Sawle P, Bains S, Hammad J, Alberto R, Foresti R, and Green CJ. CORM-A1: a new pharmacologically active carbon monoxide-releasing molecule. FASEB J 19: 284-286, 2005.

28. Nobre LS, Al Shahrour F, Dopazo J, and Saraiva LM. Exploring the antimicrobial action of a carbon monoxidereleasing compound through whole-genome transcription profiling of Escherichia coli. Microbiology 155: 813-824, 2009.

29. Nobre LS, Seixas JD, Romao CC, and Saraiva LM. Antimicrobial action of carbon monoxide-releasing compounds. Antimicrob Agents Chemother 51: 4303-4307, 2007.

30. Obirai JC, Hamadi S, Ithurbide A, Wartelle C, Nyokong T, Zagal J, Top S, and Bedioui F. UV-Visible and electrochemical monitoring of carbon monoxide release by donor complexes to myoglobin solutions and to electrodes modified with films containing hemin. Electroanalyis 1689-1695, 2006.

31. Ortiz de Montellano PR. The mechanism of heme oxygenase. Curr Opin Chem Biol 4: 221-227, 2000.

32. Pitchumony TS, Spingler B, Motterlini R, and Alberto R. Syntheses, structural characterization and $\mathrm{CO}$ releasing properties of boranocarbonate $[\mathrm{H}(3) \mathrm{BCO}(2) \mathrm{H}](-)$ derivatives. Org Biomol Chem 8: 4849-4854, 2010.

33. Ryter SW, Alam J, and Choi AM. Heme oxygenase-1/carbon monoxide: from basic science to therapeutic applications. Physiol Rev 86: 583-650, 2006.

34. Sawada M, Nakashima S, Kiyono T, Nakagawa M, Yamada J, Yamakawa H, Banno Y, Shinoda J, Nishimura Y, Nozawa $Y$, and Sakai N. p53 regulates ceramide formation by neutral sphingomyelinase through reactive oxygen species in human glioma cells. Oncogene 20: 1368-1378, 2001.

35. Sawle P, Foresti R, Mann BE, Johnson TR, Green CJ, and Motterlini R. Carbon monoxide-releasing molecules (CO$\mathrm{RMs}$ ) attenuate the inflammatory response elicited by lipopolysaccharide in RAW264.7 murine macrophages. $\mathrm{Br} \mathrm{J}$ Pharmacol 145: 800-810, 2005.

36. Sawle P, Hammad J, Fairlamb IJ, Moulton B, O’Brien CT, Lynam JM, Duhme-Klair AK, Foresti R, and Motterlini R. Bioactive properties of iron-containing carbon monoxidereleasing molecules (CO-RMs). J Pharmacol Exp Ther 318: 403-410, 2006.

37. Srisook K, Han SS, Choi HS, Li MH, Ueda H, Kim C, and Cha YN. CO from enhanced HO activity or from CORM-2 inhibits both $\mathrm{O} 2-$ and NO production and downregulates HO-1 expression in LPS-stimulated macrophages. Biochem Pharmacol 71: 307-318, 2006.

38. Suliman HB, Carraway MS, Tatro LG, and Piantadosi CA. A new activating role for $\mathrm{CO}$ in cardiac mitochondrial biogenesis. J Cell Sci 120: 299-308, 2006.

39. Taille C, El-Benna J, Lanone S, Boczkowski J, and Motterlini R. Mitochondrial respiratory chain and $\mathrm{NAD}(\mathrm{P}) \mathrm{H}$ oxidase are targets for the antiproliferative effect of carbon monoxide in human airway smooth muscle. J Biol Chem 280: 25350-25360, 2005.

40. Takamiya R, Hung CC, Hall SR, Fukunaga K, Nagaishi T, Maeno T, Owen C, Macias AA, Fredenburgh LE, Ishizaka A, Blumberg RS, Baron RM, and Perrella MA. High mobility group Box 1 contributes to lethality of endotoxemia in heme oxygenase-1 deficient mice. Am J Respir Cell Mol Biol 41: 129135, 2008.

41. Tarricone E, Scapin C, Vitadello M, Esposito F, Margonato V, Milano G, Samaja M, and Gorza L. Cellular distribution of Hsp70 expression in rat skeletal muscles. Effects of moderate exercise training and chronic hypoxia. Cell Stress Chaperones 13: 483-495, 2008.

42. Tayem Y, Johnson TR, Mann BE, Green CJ, and Motterlini R. Protection against cisplatin-induced nephrotoxicity by a carbon monoxide-releasing molecule. Am J Physiol Renal Physiol 290: F789-F794, 2006.

43. Vesely MJJ, Exon DJ, Clark JE, Foresti R, Green CJ, and Motterlini R. Heme oxygenase-1 induction in skeletal muscle cells: hemin and sodium nitroprusside are regulators in vitro. Am J Physiol 275: C1087-C1094, 1998.

44. Yi L, Morgan JT, and Ragsdale SW. Identification of a thiol/ disulfide redox switch in the human BK channel that controls its affinity for heme and CO. J Biol Chem 285: 2011720127, 2010.

45. Zhang J and Piantadosi CA. Mitochondrial oxidative stress after carbon monoxide hypoxia in the rat brain. J Clin Invest 90: 1193-1199, 1992.

46. Zuckerbraun BS, Chin BY, Bilban M, de Costa dJ, Rao J, Billiar TR, and Otterbein LE. Carbon monoxide signals via inhibition of cytochrome c oxidase and generation of mitochondrial reactive oxygen species. FASEB J 21: 1099-1106, 2007.

Address correspondence to: Dr. Mathieu Desmard Inserm U955, equipe 4 Université Paris Est Faculté de Médecine Creteil 94010

France

E-mail: desmardmathieu@yahoo.fr

Dr. Roberto Motterlini Département Anesthésie-Réanimation Chirurgicale Assistance Publique-Hôpitaux de Paris Hôpital Bichat-Claude Bernard Paris 75018

France

E-mail: roberto.motterlini@inserm.fr

Date of first submission to ARS Central, February 23, 2011; date of final revised submission, July 28, 2011; date of acceptance, July 29, 2011.

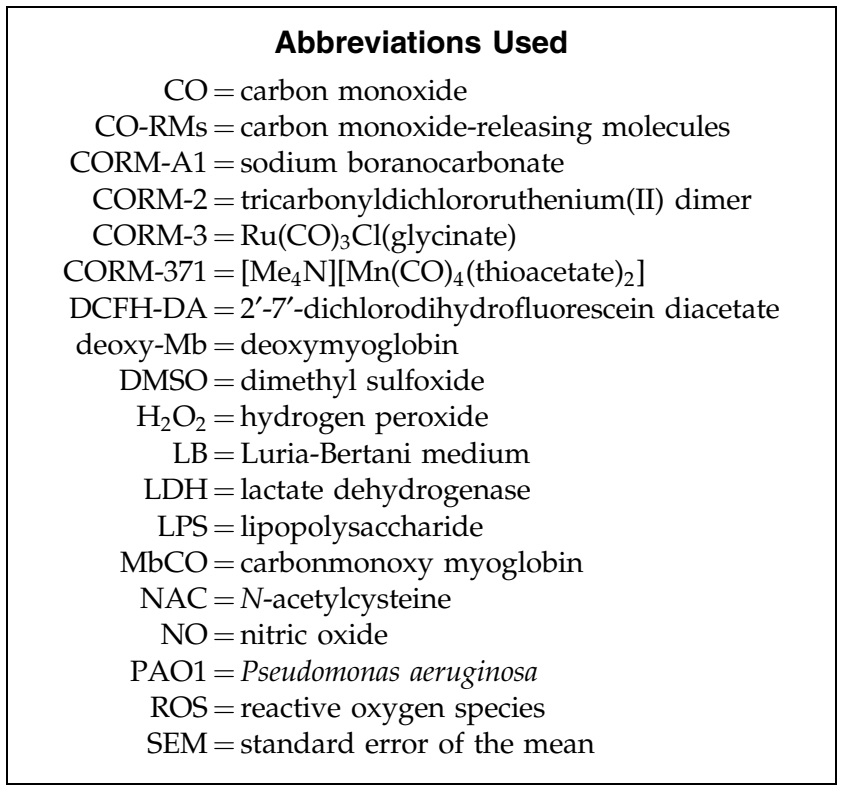


